\title{
On the Impulsive Synchronization Control for a Class of Chaotic Systems
}

\author{
Bo Wang, ${ }^{1,2}$ Peng Shi, ${ }^{3,4}$ and Xiucheng Dong ${ }^{1}$ \\ ${ }^{1}$ School of Electrical and Information Engineering, Xihua University, Chengdu 610039, China \\ ${ }^{2}$ School of Mathematics and Computer Science, Yunnan University of Nationalities, Kunming 650031, China \\ ${ }^{3}$ College of Automation, Harbin Engineering University, Harbin, Heilongjiang 150001, China \\ ${ }^{4}$ School of Engineering and Science, Victoria University, Melbourne, VIC 8001, Australia
}

Correspondence should be addressed to Bo Wang; pc_wb@163.com

Received 30 September 2014; Revised 10 December 2014; Accepted 10 December 2014; Published 28 December 2014

Academic Editor: Hamid R. Karimi

Copyright (C) 2014 Bo Wang et al. This is an open access article distributed under the Creative Commons Attribution License, which permits unrestricted use, distribution, and reproduction in any medium, provided the original work is properly cited.

\begin{abstract}
The problem on chaos synchronization for a class of chaotic system is addressed. Based on impulsive control theory and by constructing a novel Lyapunov functional, new impulsive synchronization strategies are presented and possess more practical application value. Finally some typical numerical simulation examples are included to demonstrate the effectiveness of the theoretical results.
\end{abstract}

\section{Introduction}

Chaos synchronization can be found in many areas, such as laser physics and chemical reactor. Up to now many kinds of methods have been developed to realize chaos synchronization, such as feedback control method [1-3], sliding control method [4-6], backstepping control method $[7,8]$, fuzzy control method [9-12], and adaptive control method [13-15].

Recently impulsive control theory and its application in chaos synchronization have become a research hotspot. For instance, based on impulsive control strategies, the reducedorder observer for the synchronization of generalized Lorenz chaotic systems is built in [16], the adaptive modified function projective synchronization of multiple time-delayed chaotic Rossler systems is discussed in [17], the hybrid synchronization of Lü hyperchaotic system with disturbances is investigated in [18], and the robust synchronization of perturbed Chen's fractional-order chaotic systems is studied in [19]. However, these results are just about one kind of chaotic systems, which limits their applied scope. Hence how to design the impulsive strategy to realize the synchronization suitable for more chaotic systems activates our research.
In this paper, the following class of chaotic system is introduced:

$$
\begin{gathered}
\dot{z}=f(z), \\
z\left(t_{0}^{+}\right)=z_{0},
\end{gathered}
$$

where $z(t) \in R^{n}$ is the system state vector and $f(z)$ is the nonlinear function below second order and can be transformed as follows:

$$
\begin{gathered}
\dot{z}=C+A z+B(z) z, \\
z\left(t_{0}^{+}\right)=z_{0}, \\
B_{i j}(z)=\frac{1}{2} \frac{d\left(f_{i}(z)\right)}{d z_{j}},
\end{gathered}
$$

where $A$ and $C$ are linear constant matrices and $B(z)$ is the linear matrix about $z$.

System model (2) includes some chaotic systems, such as Lorenz system, Rossler system, Chen system, and Lü system. Hence, the research on system model (2) will possess more practical application value, compared with those focused on one kind of chaotic system. 
The remainder of this paper is organized as follows. The model description and preliminaries are proposed in Section 2. Based on impulsive control theory and Lyapunov method, we shall try to propose a new and practical impulsive strategy to realize the synchronization for a class of chaotic systems in Section 3. Finally, some typical examples will be included to show the correctness of the theoretical results in Section 4, and the paper will be concluded in Section 5 .

\section{Model Description and Preliminaries}

Consider the following main chaotic system:

$$
\begin{gathered}
\dot{y}=C+A y+B(y) y, \\
y\left(t_{0}^{+}\right)=y_{0}, \\
B_{i j}(y)=\frac{1}{2} \frac{d\left(f_{i}(y)\right)}{d y_{j}},
\end{gathered}
$$

where $y(t) \in R^{n}$ is the state variable of the main system.

The slave system is

$$
\begin{gathered}
\dot{x}=C+A x+B(x) x, \quad t \neq t_{k}, \\
\Delta x=B_{k}(x-y), \quad t=t_{k}, \\
x\left(t_{0}^{+}\right)=x_{0}, \\
B_{i j}(x)=\frac{1}{2} \frac{d\left(f_{i}(x)\right)}{d x_{j}} .
\end{gathered}
$$

Define the error state variable as

$$
e(t)=x(t)-y(t) .
$$

We get the following error dynamical system:

$$
\begin{gathered}
\dot{e}=A e+B(x) x-B(y) y, \quad t \neq t_{k}, \\
\Delta e=B_{k} e, \quad t=t_{k}, \\
e\left(t_{0}^{+}\right)=e_{0} .
\end{gathered}
$$

Hence, the problem to be addressed in this paper is to design an impulsive control method such that the tracking error variable satisfies

$$
\lim _{t \rightarrow \infty}\|e(t)\|=\lim _{t \rightarrow \infty}\|x(t)-y(t)\| \longrightarrow 0 .
$$

\section{Main Results}

In this section, based on Lyapunov method and impulsive control theory, the following theoretical results are presented.

Theorem 1. For the given class of chaotic systems, based on the following impulsive control strategy

$$
a=\lambda_{\max }\left(\frac{\left(u_{k}-1\right)}{\Delta_{k} u_{k}}+\Pi^{T}+\Pi\right)<0,
$$

where

$$
\begin{gathered}
\Pi=\frac{1}{u_{k}}(A+B(x)+B(y)), \\
u_{k}=\lambda_{\max }\left[\left(I+B_{k}\right)^{T}\left(I+B_{k}\right)\right], \\
B_{k}<0, \\
\Delta_{k}=t_{k+1}-t_{k},
\end{gathered}
$$

the slave chaotic system (4) with any initial conditions will synchronize the master chaotic system (3).

Proof. Choose the following Lyapunov functional candidate:

$$
V(t)=g(t) e^{T}(t) e(t)
$$

with

$$
\begin{array}{r}
g(t)=\frac{\left(u_{k}-1\right)}{\left(t_{k+1}-t_{k}\right) u_{k}}\left(t_{k}-t\right)+\frac{1}{u_{k}}, \\
t \in\left[t_{k}, t_{k+1}\right) .
\end{array}
$$

Considering $\Delta_{k}=t_{k+1}-t_{k}$, we have

$$
\begin{array}{r}
g(t)=\frac{\left(u_{k}-1\right)}{\Delta_{k} u_{k}}\left(t_{k}-t\right)+\frac{1}{u_{k}}, \\
t \in\left[t_{k}, t_{k+1}\right) .
\end{array}
$$

When $t \in\left(t_{k}, t_{k+1}\right)$, the time derivative of $V(t)$ along the trajectories of the error dynamical system is given by

$$
\begin{aligned}
\dot{V}(t) & =\dot{g}(t) e^{T}(t) e(t)+2 g(t) e^{T}(t) \dot{e}(t) \\
& =\frac{\left(u_{k}-1\right)}{\Delta_{k} u_{k}} e^{T}(t) e(t)+2 g(t) e^{T}(t) \dot{e}(t) .
\end{aligned}
$$

For $B(e) x=B(x) e$, the error dynamical system (6) can be transformed as

$$
\begin{gathered}
\dot{e}(t)=(A+B(x)+B(y)) e(t), \quad t \neq t_{k}, \\
\Delta e(t)=B_{k} e(t), \quad t=t_{k}, \\
e\left(t_{0}^{+}\right)=e_{0} .
\end{gathered}
$$

Hence

$$
\begin{gathered}
\dot{V}(t) \leq e^{T}(t)\left(\frac{\left(u_{k}-1\right)}{\Delta_{k} u_{k}}+g(t)(A+B(x)+B(y))^{T}\right. \\
+g(t)(A+B(x)+B(y))) e(t) .
\end{gathered}
$$

It can be concluded that

$$
\begin{aligned}
\dot{V}(t) & \leq e^{T}(t)\left(\frac{\left(u_{k}-1\right)}{\Delta_{k} u_{k}}+\Pi^{T}+\Pi\right) e(t) \\
& \leq a V(t),
\end{aligned}
$$


where

$$
\Pi=\frac{1}{u_{k}}(A+B(x)+B(y)) .
$$

Hence

$$
\left(V(t) e^{-a t}\right)^{\prime}=(\dot{V}(t)-a V(t)) e^{-a t} \leq 0 .
$$

Integrating the above inequality from $t_{k}$ to $t$, we have

$$
V(t) e^{-a t} \leq V\left(t_{k}\right) e^{-a t_{k}} .
$$

Then the following inequality can be obtained:

$$
V(t) \leq V\left(t_{k}^{+}\right) \exp \left(a\left(t-t_{k}\right)\right) .
$$

Considering

$$
\begin{aligned}
V\left(t_{k}^{+}\right) & =g\left(t_{k}^{+}\right) e^{T}\left(t_{k}^{+}\right) e\left(t_{k}^{+}\right) \\
& =g\left(t_{k}^{+}\right)\left[\left(I+B_{k}\right) e\left(t_{k}^{-}\right)\right]^{T}\left[\left(I+B_{k}\right) e\left(t_{k}^{-}\right)\right] \\
& =V\left(t_{k}^{-}\right),
\end{aligned}
$$

we have

$$
V(t) \leq V\left(t_{0}^{+}\right) \exp \left(a\left(t-t_{0}\right)\right)
$$

One can obtain

$$
\|e(t)\| \leq e_{0} \exp \left(\frac{1}{2} a\left(t-t_{0}\right)\right) .
$$

Hence, it can be concluded that the error dynamical system (6) is stable. That means that the slave system (4) can synchronize with the master system (3) based on the given impulsive control strategy and this completes the proof.

Next, let $B_{k}=b I$ and $\Delta_{k}=\Delta$, and based on Theorem 1 , we can derive the following theoretical results, and its proof is omitted.

Theorem 2. For the given class of chaotic system, based on the following impulsive control strategy

$$
a=\lambda_{\max }\left(\frac{(u-1)}{\Delta \cdot u}+\Pi^{T}+\Pi\right)<0
$$

with

$$
\begin{gathered}
\Pi=\frac{1}{u}(A+B(x)+B(y)), \\
u=\lambda_{\max }\left[(I+b I)^{T}(I+b I)\right] \\
b<0,
\end{gathered}
$$

the slave chaotic system (4) with any initial conditions will synchronize with the master chaotic system (3).

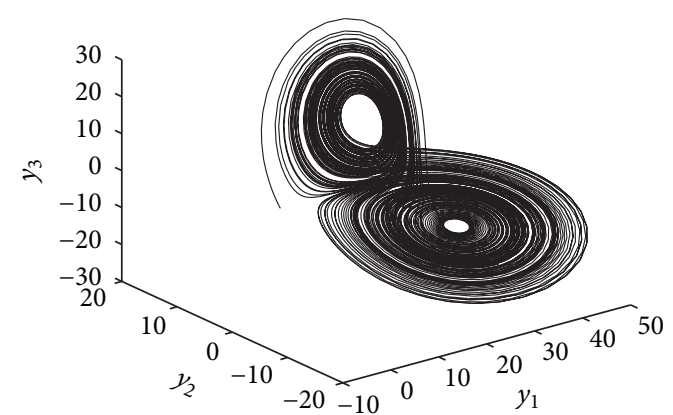

FIGURE 1: Dynamic behavior of the chaotic system in case 1.

\section{Example and Simulation}

In this section, we will verify the proposed methodology by giving two illustrative examples. First consider the unified chaotic system as follows:

$$
\begin{aligned}
& \dot{z}_{1}=(25 r+10)\left(z_{2}-z_{1}\right), \\
& \dot{z}_{2}=(28-35 r) z_{1}-z_{1} z_{3}+(29 r-1) z_{2}, \\
& \dot{z}_{3}=z_{1} z_{2}-\frac{r+8}{3} z_{3} .
\end{aligned}
$$

It can be transformed as

$$
\dot{z}=C+A z+B(z) z
$$

with

$$
\begin{aligned}
& A=\left[\begin{array}{ccc}
-25 r-10 & 25 r+10 & 0 \\
28-35 r & 29 r-1 & 0 \\
0 & 0 & -\frac{r+8}{3}
\end{array}\right] \text {, } \\
& B(z)=\frac{1}{2}\left[\begin{array}{ccc}
0 & 0 & 0 \\
-z_{3} & 0 & -z_{1} \\
z_{2} & z_{1} & 0
\end{array}\right], \quad C=\left[\begin{array}{l}
0 \\
0 \\
0
\end{array}\right] \text {. }
\end{aligned}
$$

Unified chaotic system has different dynamic behavior with different parameter $r$. For instance, the unified chaotic system represents Lü system when $r=0.8$, Lorenz system when $0 \leq$ $r<0.8$, and Chen system when $0.8<r \leq 1$.

The numerical simulation is with initial condition $x_{0}=$ $[7,9,2]^{T}, y_{0}=[-1,3,5]^{T}$, and the simulation step 0.001 second. Based on Theorem 2, we choose the impulsive control parameters $\Delta=0.02, b=-0.8$.

Remark 3. Figure 1 depicts the dynamic behavior of the chaotic system in case 1 . It can be seen that the state variable moves in a scope and will never converge to a constant with the lapse of time. Figure 2 depicts the time response of the error variable of master-salve system in case 1 . It can be seen that the error variable closes to zero quickly based on the given impulse control method, which verifies the correctness of our theoretical results. 

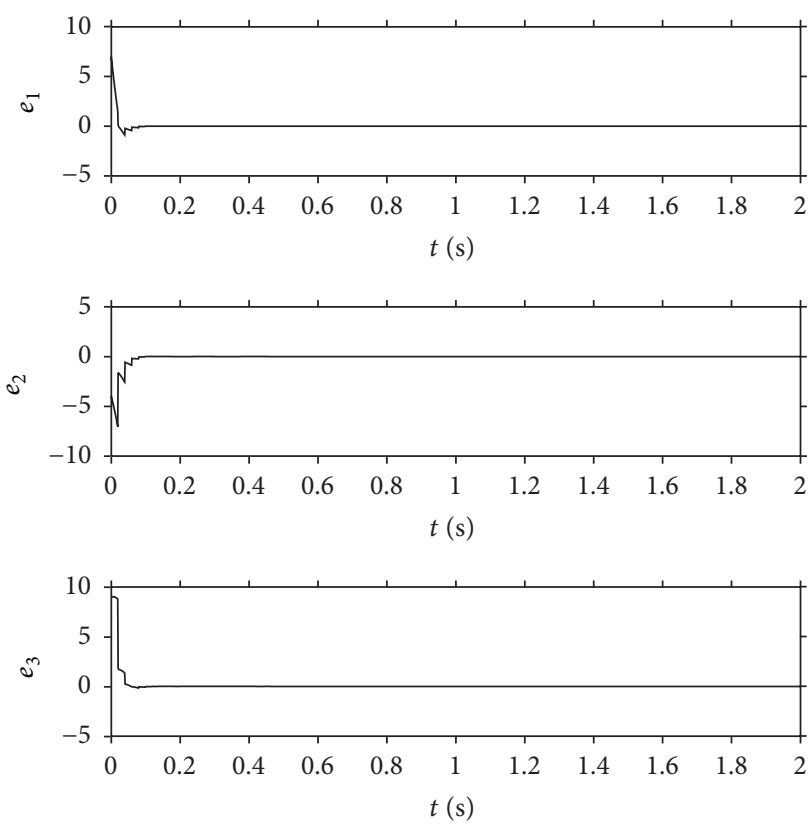

FIGURE 2: Time response of the error variable in case 1.

Next, consider the following Rossler system

$$
\begin{aligned}
& \dot{z}_{1}=-z_{2}-z_{3}, \\
& \dot{z}_{2}=z_{1}+0.15 z_{2}, \\
& \dot{z}_{3}=0.2+z_{3}\left(z_{1}-10\right) .
\end{aligned}
$$

It can be transformed as follows:

$$
\dot{z}=C+A z+B(z) z
$$

with

$$
\begin{gathered}
A=\left[\begin{array}{ccc}
0 & -1 & -1 \\
1 & 0.15 & 0 \\
0 & 0 & -10
\end{array}\right], \quad B(z)=\frac{1}{2}\left[\begin{array}{ccc}
0 & 0 & 0 \\
0 & 0 & 0 \\
z_{3} & 0 & z_{1}
\end{array}\right], \\
C=\left[\begin{array}{c}
0 \\
0 \\
0.2
\end{array}\right] .
\end{gathered}
$$

The numerical simulation is with initial condition $x_{0}=$ $[-1,5,-4]^{T}, y_{0}=[7,-6,2]^{T}$ and the simulation step 0.001 second. Based on Theorem 2, we choose the impulsive control parameters $\Delta=0.02$ and $b=-0.8$.

Remark 4. Figure 3 depicts the dynamics of the chaotic system in case 2. Figure 4 depicts the time response of the error variable of master-salve system in case 2 . It can be seen that the error variable converges to zero quickly based on the proposed impulse control method.

From the above numerical simulations, it can be concluded that our impulsive synchronization strategy has more practical application value compared with those specific to one kind of chaotic system.

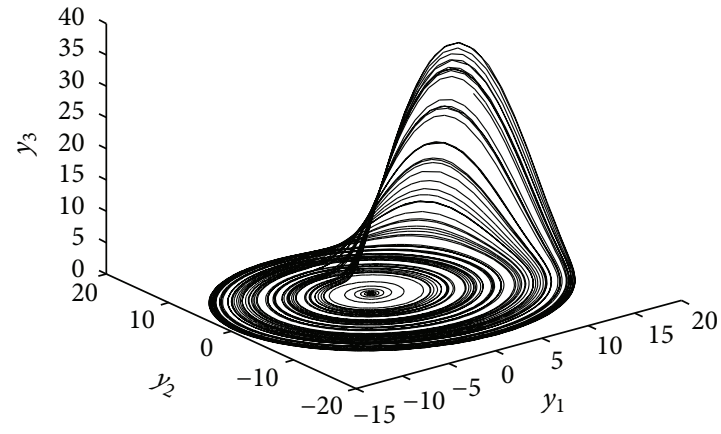

Figure 3: Dynamical behavior of the chaotic system in case 2 .
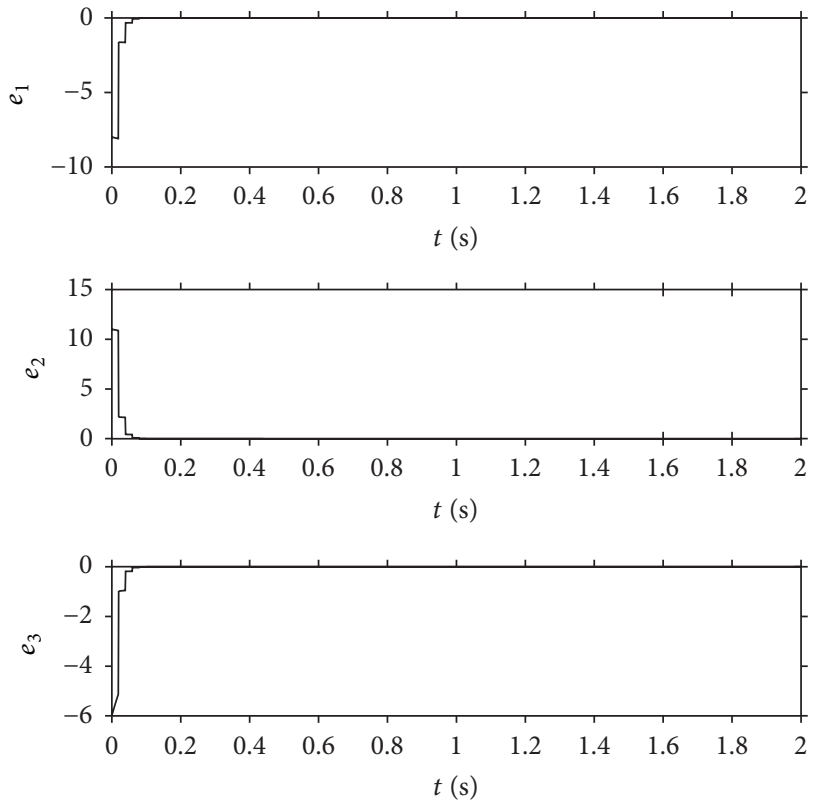

FIgURE 4: Time response of the error state variable in case 2.

\section{Conclusions}

This paper focuses on the chaos synchronization problem and tries to figure out the strategies suitable for more chaotic systems. Based on the impulsive control technique and Lyapunov stability theory, we have presented the new impulsive synchronization strategies for a class of chaotic systems. Finally some numerical simulations have been carried out to demonstrate the effectiveness of our theoretical results.

\section{Conflict of Interests}

The authors declare that there is no conflict of interests regarding the publication of this paper.

\section{Acknowledgments}

This work was partially supported by the Australian Research Council (DP140102180, LP140100471), the 111 Project (B12018), the Open Research Fund of Ministry 
of Education (SZjj2011-006), the Chunhui Plan Project of Ministry of Education (Z2011089, Z2014055), Xihua University Young Scholars Training Program (01201419), the Open Research Subject of Key Laboratory of Signal and Information Processing of Sichuan Province (szjj2014-018), and the National Natural Science Foundation of China (61174058, 61134001, and 11461062).

\section{References}

[1] A. E. Matouk, "Chaos, feedback control and synchronization of a fractional-order modified autonomous Van der Pol-Duffing circuit," Communications in Nonlinear Science and Numerical Simulation, vol. 16, no. 2, pp. 975-986, 2011.

[2] D. Chen, P. Shi, and X. Ma, "Control and synchronization of chaos in an induction motor system," International Journal of Innovative Computing, Information and Control, vol. 8, no. 10, pp. 7237-7248, 2012.

[3] H. R. Karimi and H. Gao, "New delay-dependent exponential $H_{\infty}$ synchronization for uncertain neural networks with mixed time delays,' IEEE Transactions on Systems, Man, and Cybernetics Part B, vol. 40, no. 1, pp. 173-185, 2010.

[4] M. Heydari, H. Salarieh, and M. Behzad, "Stochastic chaos synchronization using unscented Kalman-Bucy filter and sliding mode control," Mathematics and Computers in Simulation, vol. 81, no. 9, pp. 1770-1784, 2011.

[5] A. Razminia and D. Baleanu, "Complete synchronization of commensurate fractional order chaotic systems using sliding mode control," Mechatronics, vol. 23, no. 7, pp. 873-879, 2013.

[6] H. R. Karimi, "A sliding mode approach to $H_{\infty}$ synchronization of master-slave time-delay systems with Markovian jumping parameters and nonlinear uncertainties," Journal of the Franklin Institute, vol. 349, no. 4, pp. 1480-1496, 2012.

[7] Y. Yu and H.-X. Li, "Adaptive hybrid projective synchronization of uncertain chaotic systems based on backstepping design," Nonlinear Analysis: Real World Applications, vol. 12, no. 1, pp. 388-393, 2011.

[8] N. Chen, F. Song, G. Li, X. Sun, and C. Ai, "An adaptive sliding mode backstepping control for the mobile manipulator with nonholonomic constraints," Communications in Nonlinear Science and Numerical Simulation, vol. 18, no. 10, pp. 2885-2899, 2013.

[9] M. Chadli, H. R. Karimi, and P. Shi, "On stability and stabilization of singular uncertain Takagi-Sugeno fuzzy systems," Journal of the Franklin Institute, vol. 351, no. 3, pp. 1453-1463, 2014.

[10] A. I. Al-Odienat, "The PID controller based on genetic algorithm for voltage stability of the synchronous machine," International Journal of Innovative Computing, Information and Control, vol. 10, pp. 2263-2276, 2014.

[11] M. Chadli, I. Zelinka, and T. Youssef, "Unknown inputs observer design for fuzzy systems with application to chaotic system reconstruction," Computers \& Mathematics with Applications, vol. 66, no. 2, pp. 147-154, 2013.

[12] H. R. Karimi, M. Zapateiro, and N. Luo, "Stability analysis and control synthesis of neutral systems with time-varying delays and nonlinear uncertainties," Chaos, Solitons and Fractals, vol. 42, no. 1, pp. 595-603, 2009.

[13] I. Zelinka, M. Chadli, D. Davendra, R. Senkerik, and R. Jasek, "An investigation on evolutionary reconstruction of continuous chaotic systems," Mathematical and Computer Modelling, vol. 57, no. 1-2, pp. 2-15, 2013.

[14] U. E. Vincent and R. Guo, "Finite-time synchronization for a class of chaotic and hyperchaotic systems via adaptive feedback controller," Physics Letters, Section A: General, Atomic and Solid State Physics, vol. 375, no. 24, pp. 2322-2326, 2011.

[15] H. R. Karimi, M. Zapateiro, and N. Luo, "Adaptive synchronization of master-slave systems with mixed neutral and discrete time-delays and nonlinear perturbations," Asian Journal of Control, vol. 14, no. 1, pp. 251-257, 2012.

[16] Z. Zhang, H. Shao, Z. Wang, and H. Shen, "Reduced-order observer design for the synchronization of the generalized Lorenz chaotic systems," Applied Mathematics and Computation, vol. 218, no. 14, pp. 7614-7621, 2012.

[17] K. S. Sudheer and M. Sabir, "Adaptive modified function projective synchronization of multiple time-delayed chaotic Rossler system," Physics Letters A, vol. 375, no. 8, pp. 1176-1178, 2011.

[18] Q. Li, R. Dong, and B. Lu, "Hybrid synchronization of Lü hyperchaotic system with disturbances by sliding mode control," Procedia Engineering, vol. 15, pp. 23-27, 2011.

[19] M. Asheghan, M. Beheshti, and M. Tavazoei, "Robust synchronization of perturbed Chen's fractional-order chaotic systems," Communications in Nonlinear Science and Numerical Simulation, vol. 16, pp. 1044-1051, 2011. 


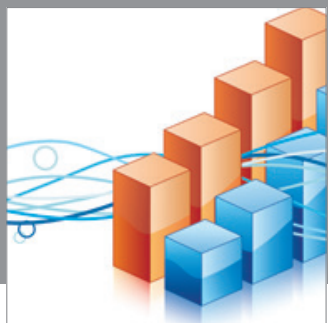

Advances in

Operations Research

mansans

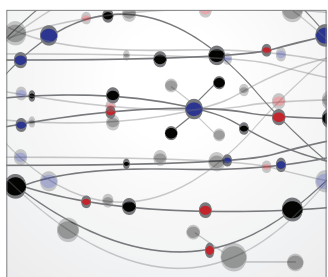

The Scientific World Journal
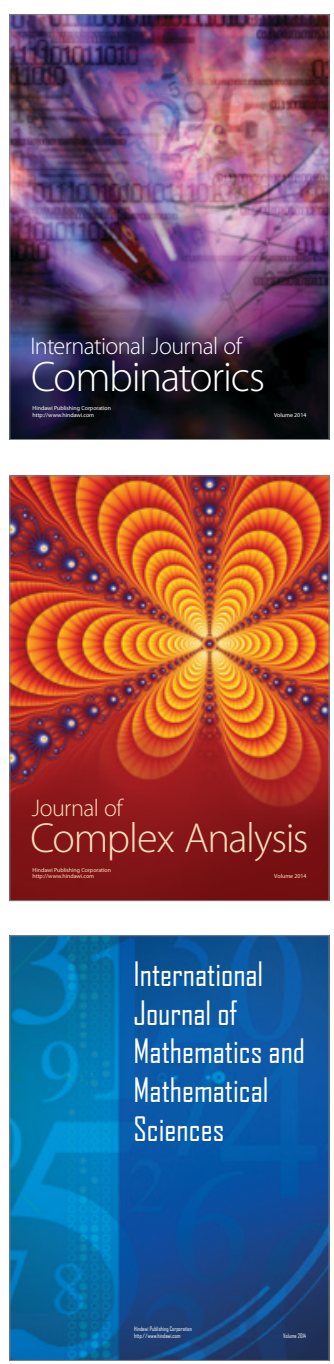
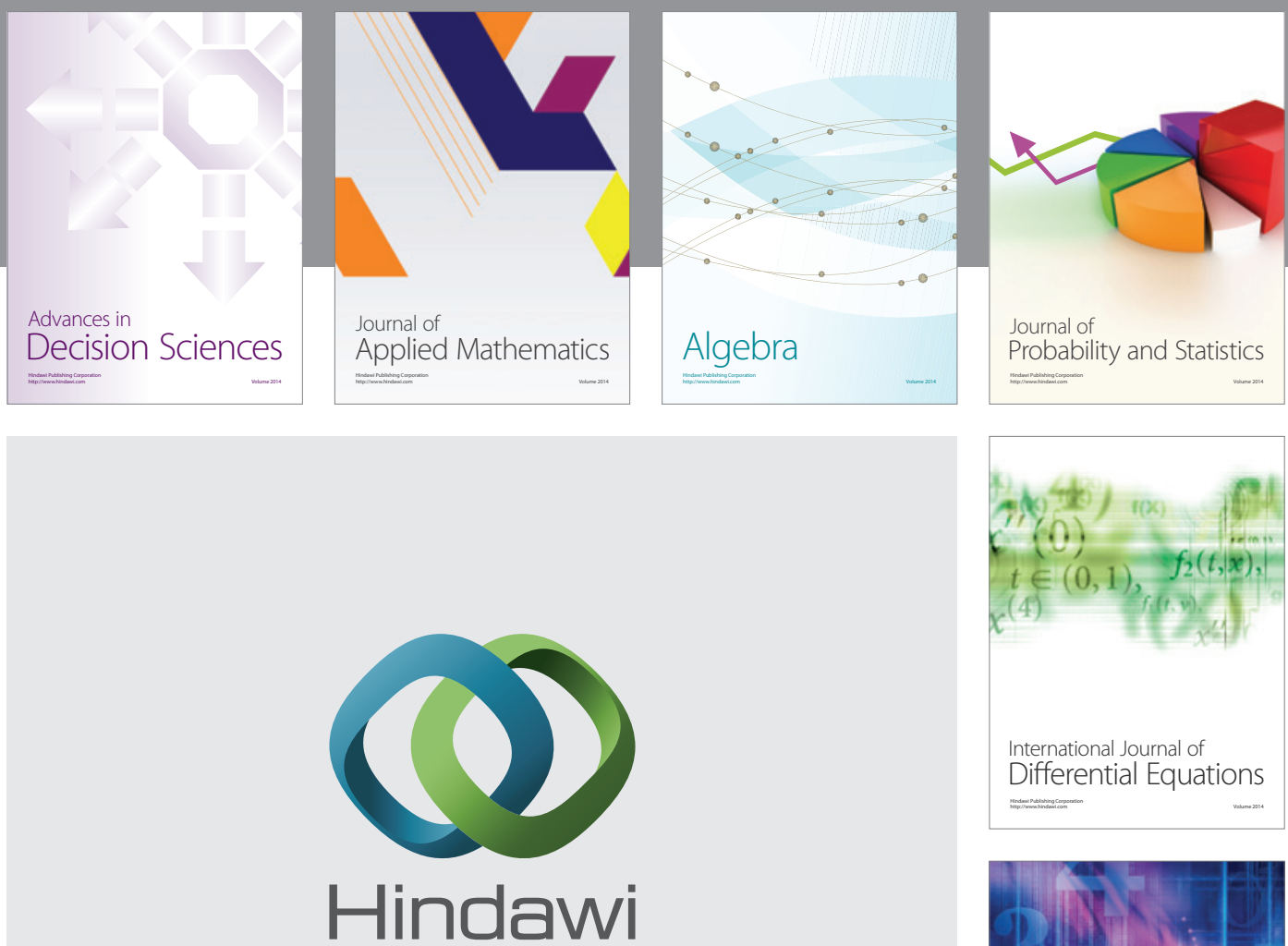

Submit your manuscripts at http://www.hindawi.com
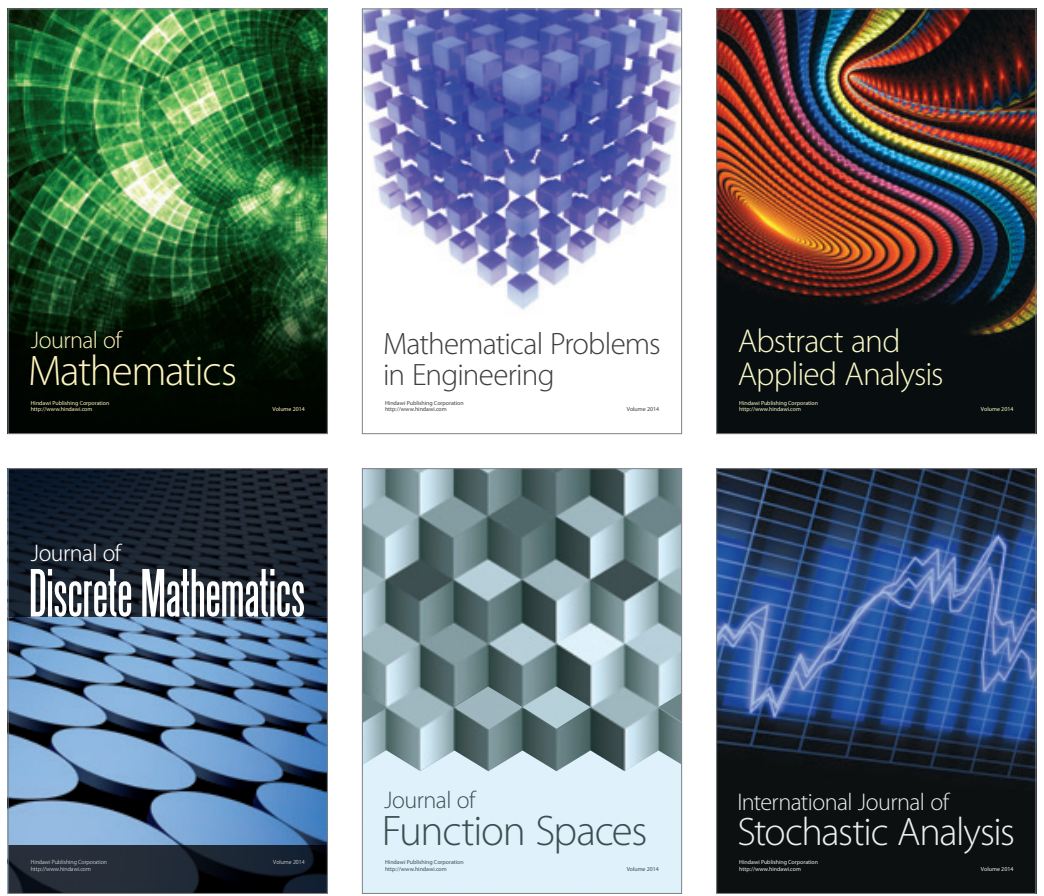

Journal of

Function Spaces

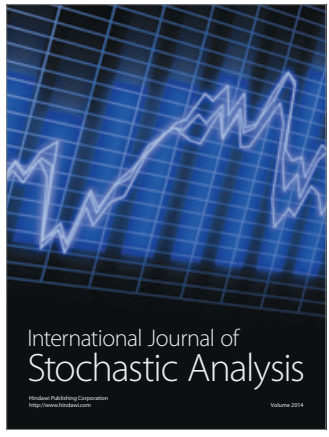

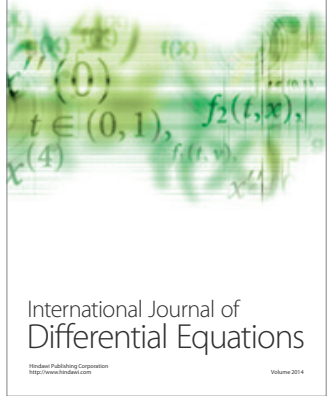
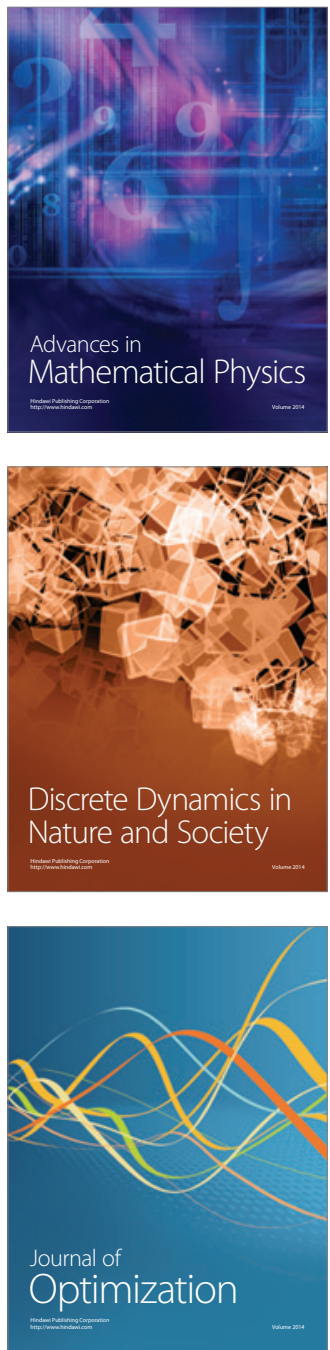